\title{
Evolution of C-O-H phases in the deep mantle -derived garnets
}

\author{
S. DAS ${ }^{1 *}$ AND A. R. BASU ${ }^{1}$
}

${ }^{1}$ Dept. of Earth and Environmental Sciences, Univ. of Texas at Arlington, TX 76019, USA ( ${ }^{*}$ correspondence: souvikdasgeology@gmail.com)

The speciation of the various C-O-H phases is linked with the oxygen fugacity variation in the mantle that have profound effect in Earth's geochemical cycle and the carbon budget. The deep carbon in the Earth's mantle is considered to form either by carbonate reduction or hydrocarbon (C-H) oxidation. The principal challenge, however, is to document the pathways of $\mathrm{C}-\mathrm{O}-\mathrm{H}$ evolution in natural samples of the mantle. Here we report textural evidence showing transition of hydrocarbon (C-H) to carbon (C) and carbon-dioxide $\left(\mathrm{CO}_{2}\right)$ in deep mantle -derived garnets. This evolution of C$\mathrm{O}-\mathrm{H}$ fluids during majoritic garnet breakdown is preserved in the Alpe Arami Garnet peridotite of the Swiss Alps. Our observations indicate that hydrocarbons from reduced deep mantle can produce $\mathrm{C}$ and $\mathrm{CO}_{2}$ by progressive oxidation. 